\title{
The relationship between different price indices: Evidence from Turkey
}

\author{
Yilmaz Akdi ${ }^{\mathrm{a}}$, Hakan Berument ${ }^{\mathrm{b}, *}$, Seyit Mümin Cilasun ${ }^{\mathrm{c}}$ \\ ${ }^{a}$ Department of Statistics, Faculty of Science, Ankara University, 06100 Tandogan Ankara, Turkey \\ ${ }^{\mathrm{b}}$ Department of Economics, Bilkent University, 06800 Bilkent Ankara, Turkey \\ ${ }^{\mathrm{c}}$ Department of Economics, Atilim University, 06836 Incek Ankara, Turkey
}

Received 25 February 2005; received in revised form 4 May 2005

Available online 14 June 2005

\begin{abstract}
A possible relationship between the Consumer Price Index and the Wholesale Price Index has been analyzed for long and short-run relationships. Conventional Engle and Granger [Estimation Test Econ. 55(1987) 2251-276] and Johansen's [J. Econ. Dyn. Control 12 (1988) 231-254] cointegration tests give mixed evidence for a possible long-run relationship between those two series. The model-free and seasonally robust periodogram-based test fails to reject the null of no-cointegration relationship. However, these two series move together in the short run.
\end{abstract}

(C) 2005 Elsevier B.V. All rights reserved.

Keywords: Cointegration; Periodogram; Price indices

\section{Introduction}

Inflation or price level targeting is becoming more popular as a policy goal among central banks for guiding their monetary policies. The selection of the basket on which price level is calculated is as vital as the level of targeted inflation rate because

\footnotetext{
*Corresponding author. Tel.: + 903122902342 ; fax: + 903122665140

E-mail address: berument@bilkent.edu.tr (H. Berument).
} 
different indices could yield different inflation rates. Various central banks used different baskets to implement their policies.

The price indices are the weighted averages of the prices of individual items. These prices are not all affected in the same way by the policies of central banks. For example, central banks' exchange rate policies are more likely to affect the prices of tradable than non-tradable goods. Moreover, central bank interest rate policies affect the prices of goods and services differently (services are less likely to be affected by the interest rates relative to goods prices). Therefore, the selection of the price index could be detrimental to the credibility of the central bank policies as well as to their success.

The purpose of this study is to assess any long- and short-run relationships between two widely used indexes: the Consumer Price Index (CPI) and the Wholesale Price Index (WPI) series. The CPI includes both tradable goods and nontradable goods/services in its composition; however, the WPI consists only of tradable goods. It might be the case that these two indexes are affected differently by exchange rate and interest rate-based policies. Therefore, it is plausible that these two indexes do not move together. If these two indexes are not cointegrated - there is no long-run relationship, then this means their values may diverge persistently over time. Therefore, the announced inflation target might be reached for some of the price indexes but missed for some others. This will threaten the credibility of the Central Bank. In order to avoid that, the selection of the price index is vital for the implementation and success of any inflation target-based monetary policy. However, if there is a short-run relationship, this means their long-run deviation will not affect their respective behaviors in the short run.

To the best of our knowledge, there is no other study that looks at the relationship between different price indexes. On the other hand, there are various studies that suggest that these series are affected differently by various economic shocks. For example, technology shocks and increasing return to scale [1]; different stickiness of intermediate product prices [2]; tight monetary policy [3]; oil price shocks [4]; and real exchange rates [5] affect the prices of different products differently. The purpose of this paper is to analyze the dynamic relationship between these two series directly rather than assessing the third variable effect on these two series.

This paper studies a direct relationship between the two most popular price indexes (WPI and CPI) using Turkish data, which has various advantages. Firstly, Turkey has been experiencing a high and persistent level of inflation without running into hyperinflation since the mid-1970s. The high variability in the level of inflation allows us to minimize the type 2 error-an error made when an incorrect null hypothesis is not rejected. Secondly, unlike some central banks, the Central Bank of the Republic of Turkey used both exchange rate and interest rate-based stabilization policies to hamper inflation. Therefore, the effects on prices of both central bank policy tools do exist for the Turkish data. Thirdly, Turkey has relatively well-developed and liberal markets; therefore, prices move with market forces rather than being regulated by price controls or freezes. All these allow the use of the Turkish data for any relationship that could exist among price indexes. 
This study, in particular, investigates a possible relationship between the WPI and CPI series for the period January 1987-August 2004 in Turkey by using conventional cointegration tests such as Engle and Granger's [6] single equation, Johansen's [7] multivariate cointegration tests as well as the periodogram-based cointegration test. The main contribution of this paper is to use this third test to determine if there is a (long run) relationship between these two indexes. Note that both the CPI and the WPI are quite seasonal series. Maravall [8], Hecq [9], Cubadda [10] and Cheung and Westermann [11] argue that addressing the seasonality in the data could alter the basic inference gathered from the data. In order to account for this, we used the periodogram-based cointegration tests as developed by Akdi [12], and Akdi and Dickey [13]. This method has the advantage of being model free and seasonally robust. The next section introduces the data and the conventional as well as the periodogram-based testing methods, Section 3 presents the empirical evidence and the last section concludes the paper.

\section{Data}

The WPI and CPI indexes for the period from 1987:01 to 2004:08 were gathered from the Central Bank of the Republic of Turkey data delivery system (http: //tcmbf40.tcmb.gov.tr/cbt.html). In our analysis, we used 1994-based WPI and CPI indexes. The WPI index includes 678 goods chosen according to the share of sales values that are produced domestically and supplied to the domestic markets. The current prices of those goods are followed from 1287 firms with the highest domestic endorsement. The prices, except for the agriculture sector, are the final goods prices. For the agriculture sector, prices are taken from wholesale food markets. The 1994based WPI uses ISIC Rev.3. classification and is calculated by employing fixedweight Laspeyres formulation. The 1994-based CPI index, on the other hand, is calculated for seven geographical provinces and 19 cities by employing fixed-weight Laspeyres formulation. It covers 410 goods and services whose prices are gathered from 35 residential areas and uses Classification of Individual Consumption by Purpose.

Fig. 1(a) reports the time series plots of the logarithms of these two series. These series are similar regarding persistency and both have increasing trends. The graphs of the calculated values of Autocorrelation and Partial Autocorrelation functions are reported in Fig. 1(b) for the sample. Graphs of the autocorrelation functions decay very slowly, which may suggest a possible unit root for each series. Therefore, the unit root tests are warranted.

Table 1 reports the conventional Dickey-Fuller, Phillips-Peron Unit Root Tests as well as Dickey et al. (1984) seasonal unit root tests for these two series. Panel A reports the series with an intercept term, Panel $\mathrm{B}$ gives the intercept term and the time trend and Panel $\mathrm{C}$ reports the tests on the first difference of the series for the Dickey-Fuller, Phillips-Peron Unit Root Tests and the twelfth difference for the Dickey, Hasza and Fuller test. Table 1 suggests that we cannot reject the null of a unit root in either series in levels (with and without time trend). However, we could 


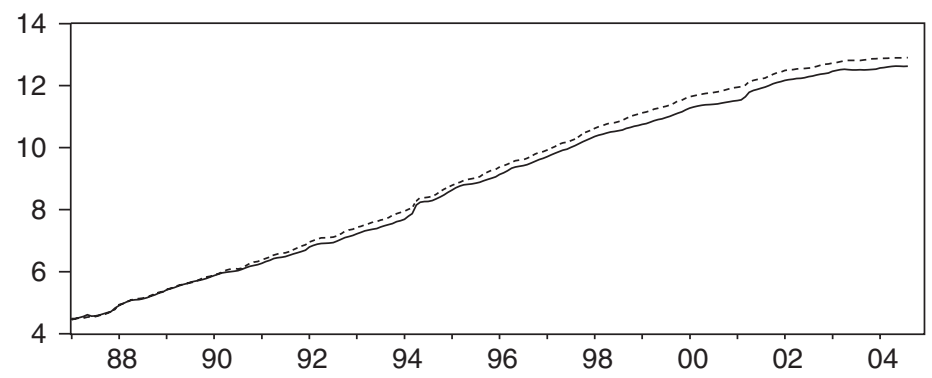

(a) WPI (Solid line) and CPI (Dotted line)

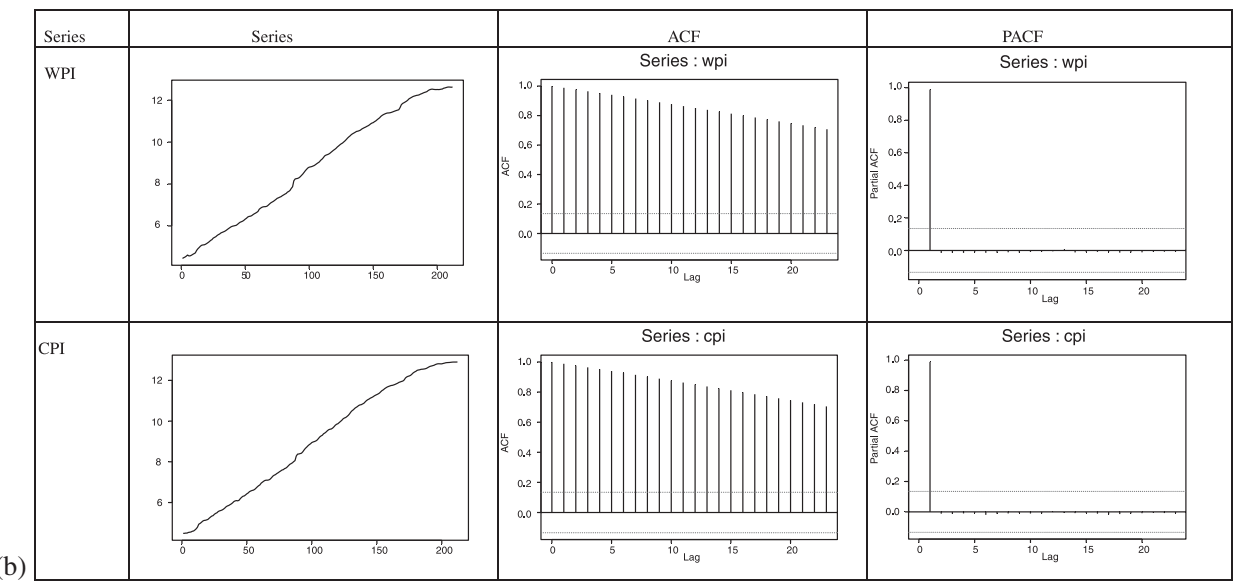

Fig. 1. (a) WPI and CPI figures. WPI (Solid line) and CPI (Dotted line). (b) Identification plots of WPI and CPI.

Table 1

Unit root tests

\begin{tabular}{|c|c|c|c|c|c|c|c|c|c|}
\hline & \multicolumn{3}{|c|}{ A: Intercept } & \multicolumn{3}{|c|}{ B: Intercept with trend } & \multicolumn{3}{|c|}{ C: Difference with interecept } \\
\hline & $\mathrm{ADF}$ & PP & $\operatorname{DHF}(12)$ & $\mathrm{ADF}$ & PP & $\operatorname{DHF}(12)$ & $\mathrm{ADF}$ & PP & $\operatorname{DHF}(12)$ \\
\hline WPI & -1.82 & -1.88 & -1.54 & 0.80 & 0.99 & 0.82 & $-5.26^{* *}$ & $-8.22 * *$ & $-5.92 * *$ \\
\hline CPI & -2.62 & -2.37 & -1.74 & 2.53 & 2.44 & 1.03 & $-4.25^{* *}$ & $-8.19 * *$ & $-7.99 * *$ \\
\hline
\end{tabular}

Note: * indicates the level of significance at $5 \%$ and ** indicates the level of significance at $1 \%$. The critical values are gathered from Hamilton [14] and Franses and Hobijn [15].

reject the null of a unit root in the differenced of the series. Thus, we claim that both series are $\mathrm{I}(1)$.

Next, we will perform the Akdi and Dickey's [13] periodogram-based unit root test for each series. For this test, one may use the trigonometric transformation of the 
series. Given a time series $\left\{Y_{1}, Y_{2}, \ldots, Y_{n}\right\}$, the periodogram ordinate (without any model specification) is

$$
I_{n}\left(w_{k}\right)=\frac{n}{2}\left(a_{k}^{2}+b_{k}^{2}\right),
$$

where $a_{k}, b_{k}$ are the Fourier coefficients and defined as

$$
a_{k}=\frac{2}{n} \sum_{t=1}^{n}\left(Y_{t}-\bar{Y}\right) \cos \left(w_{k} t\right) \quad \text { and } \quad b_{k}=\frac{2}{n} \sum_{t=1}^{n}\left(Y_{t}-\bar{Y}\right) \sin \left(w_{k} t\right) .
$$

Note that when $w_{k}=2 \pi k / n$, the following equality appears

$$
\sum_{t=1}^{n} \cos \left(w_{k} t\right)=\sum_{t=1}^{n} \sin \left(w_{k} t\right)=0
$$

and this causes the Fourier coefficients to be invariant to the mean and therefore the periodogram ordinate is invariant to the mean. Moreover, periodogram-based unit root/cointegration tests have the advantage of being seasonally robust, and model free from the selection of the lag lengths (see Refs. [12,13]). ${ }^{1}$

In order to reject the null hypothesis of a unit root, one needs to observe small values of the periodogram ordinates. Therefore, the values of the test statistics, $T\left(w_{k}\right)$ can be used to test for a unit root where

$$
T\left(w_{k}\right)=\frac{2\left(1-\cos \left(w_{k}\right)\right)}{\hat{\sigma}^{2}} I_{n}\left(w_{k}\right) .
$$

The test statistic is distributed as a mixture of chi-squares exactly for AR(1) series under the assumption of non-stationarity. In this case, the normalized periodogram will be distributed as chi-squares with two degrees of freedom asymptotically under the assumption of stationarity. In conventional tests, the power of the tests is not exact. However, the power can be calculated analytically for the periodogram method to test for a unit root (see Ref. [12]). For higher order series, the same distribution is obtained asymptotically; that is

$$
T\left(w_{k}\right)=\frac{2\left(1-\cos \left(w_{k}\right)\right)}{\hat{\sigma}^{2}} I_{n}\left(w_{k}\right) \stackrel{D}{\longrightarrow} Z_{1}^{2}+3 Z_{2}^{2},
$$

where $Z_{1}$ and $Z_{2}$ are independent standard normal random variables and $\sigma^{2}$ is the variance of the error term. Here, the notation " $\longrightarrow$ " stands for convergence in distribution. The critical values of this distribution are provided by Akdi and Dickey [13]. The results of both types of series are given in Table 2.

Table 2 suggests that both series are again I(1).

\footnotetext{
${ }^{1}$ The periodogram-based method has certain advantages over conventional tests. Firstly, conventional tests require the estimation of too many AR parameters to account for the dynamics/seasonality of the series. Secondly, test results change with the sample size in conventional tests, while the periodogrambased method requires no parameter estimation except for variance. Thirdly, the critical values of the test statistics are free of sample size constraints. Thus, these might have considerable advantages, especially for small samples.
} 
Table 2

Periodogram-based unit root test

\begin{tabular}{llllll}
\hline Series & $I_{n}\left(w_{1}\right)$ & $\hat{\sigma}^{2}$ & $T_{n}\left(w_{1}\right)$ & Critical values & Conclusion \\
\hline In level & & & & & \\
WPI & 974.803 & 0.00079 & 1083.79 & 0.178 & Unit root \\
CPI & 1064.58 & 0.00067 & 1395.60 & 0.178 & Unit root \\
Difference & & & & & \\
WPI & 0.017692 & 0.00061 & 0.025716 & 0.178 & Stationary \\
CPI & 0.023725 & 0.00063 & 0.033391 & 0.178 & Stationary \\
\hline
\end{tabular}

\section{Empirical evidence}

This section provides the test statistics for the long- and short-run relationships between CPI and WPI series.

\subsection{Long-run relationships: Cointegration tests}

In the previous section, it was suggested that the two series are integrated in the same order; in other words, they may have a common trend. In such cases, it is reasonable to search for a possible cointegrating relationship between CPI and WPI series. If a set of non-stationary multivariate time series has a stationary linear combination, then that series is considered cointegrated. Briefly, if a series $\underline{Y}_{t}$ is nonstationary and there is a $\underline{\beta}$ vector (or matrix) such that $W_{t}=\underline{\beta}^{\prime} \underline{Y}_{t}$ becomes stationary, then $\underline{Y}_{t}$ is considered cointegrated and the vector $\underline{\beta}$ is called the cointegrating vector.

In this study, it was suggested that both WPI and CPI are I(1). Thus, these nonstationary series can be written as a linear combination of stationary and nonstationary series as

$$
\begin{aligned}
& C P I_{t}=a_{11} U_{t}+a_{12} S_{t}, \\
& W P I_{t}=a_{21} U_{t}+a_{22} S_{t},
\end{aligned}
$$

where $U_{t}$ and $S_{t}$ represent the unit root and stationary component of these series, respectively. Since each component of the bivariate series includes the non-stationary component $U_{t}$, both components of $\underline{Y}_{t}$ are non-stationary. However, if the coefficients $\left(a_{i j}, i, j=1,2\right)$ in Eq. (5) are known, then

$$
W P I_{t}-\frac{a_{21}}{a_{11}} C P I_{t}=\left(a_{22}-\frac{a_{21} a_{12}}{a_{11}}\right) S_{t}=c S_{t}
$$

is stationary and the system is cointegrated with the cointegrating vector $\beta=\left(-\left(a_{21} / a_{11}\right), 1\right)^{\prime}$. Since we do not know the coefficients, we need to estimate all the coefficients in Eq. (5). Instead, it is sufficient to estimate the ratio $a_{21} / a_{11}$ with the 


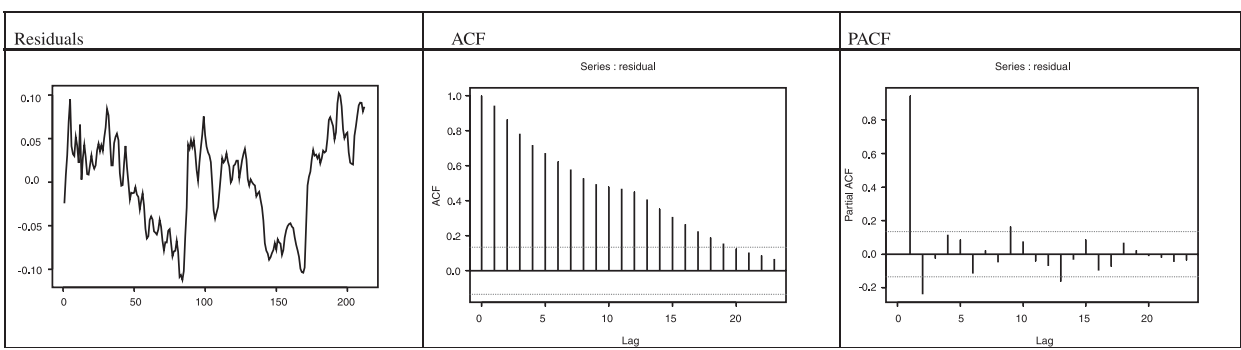

Fig. 2. Residual plots from OLS.

OLS method. The differenced series in (6) looks like the residuals from the regression of WPI on CPI and hence if the residual series is stationary, then the bivariate series is cointegrated. Moreover, the OLS estimator of the parameter CPI obtained from that regression is a consistent estimator for the ratio $a_{21} / a_{11}$ (Ref. [6]).

The graphs of the residual of this regression are given in Fig. 2. The regression coefficient is calculated as 0.958707 . Therefore, if this residual series is stationary, then the cointegration vector will be $(-0.958707,1)^{\prime}$.

We first performed the Engle-Granger cointegration test. The ADF test statistics for the residual term when the WPI is regressed on the CPI index is -2.035. Thus, we rejected the no-cointegration at the $10 \%$ level but could not reject the null of nocointegration at the $5 \%$ level. Next, we performed the Johansen cointegration test. The test results are reported in Tables $3 a$ and $b$.

Table 3a reports the results of Johansen's cointegration tests. The test statistics suggest that we can reject the null hypothesis if there is no-cointegrating relationship between the two series with the $\lambda$-trace test, but we cannot reject the null of the nocointegration with the $\lambda$-max test at the $5 \%$ level. However, we can reject the null of no-cointegration at the $10 \%$ level for both tests. Thus, the results are mixed. Table $3 \mathrm{~b}$ reports the seasonal cointegration test statistics as suggested by Johansen and Schaumburg [17] and Darné [16]. ${ }^{2}$ The test statistics can reject the null hypothesis of no-cointegration at the $5 \%$ level.

Now we apply the periodogram method proposed by Akdi [12] to determine if there is a cointegrating relationship between these two series. When the real part of the cross periodogram ordinate of the WPI and CPI series (say $y_{k}$ ) is regressed on the periodogram of the WPI (or CPI) series (say $x_{k}$ ), the coefficient of $x_{k}$ is also a consistent estimator for the ratio $a_{21} / a_{11}$ [12]. That is, when we consider the model

$$
y_{k}=\alpha+\beta x_{k}+\eta_{k}, \quad k=1,2,3, \cdots,[n / 2]
$$

the OLS estimator of $\beta$ is a consistent estimator for the ratio $a_{21} / a_{11}$ and is calculated as $\hat{\beta}_{P}=0.956865$. Here, $[n / 2]$ denotes the integer part of $n / 2$. If the series $Z_{t}=$ $Y_{2, t}-0.956865 Y_{1, t}$ is stationary, then these two series are cointegrated. If $Z_{t}$ is stationary, we will conclude that the CPI and WPI series are cointegrated. In order

\footnotetext{
${ }^{2}$ To the best of our knowledge, this test is available only for $\lambda$-max statistics but not $\lambda$-trace statistics.
} 
Table 3a

Johansen's cointegration test results

\begin{tabular}{lllccc}
\hline $\begin{array}{l}\text { Hypothesized } \\
\text { no. of CE(s) }\end{array}$ & Eigenvalue & $\begin{array}{l}\lambda \text {-trace } \\
\text { statistic }\end{array}$ & $\lambda$ max statistic & $\begin{array}{l}\lambda \text { trace test at } \\
5 \%\end{array}$ & $\begin{array}{l}\lambda \text { max test at } \\
5 \%\end{array}$ \\
\hline None $^{\mathrm{a}}$ & 0.057408 & 17.53456 & 12.23829 & 15.49471 & 14.26460 \\
${\text { At most } 1^{\mathrm{a}}}^{0.025261}$ & 5.29626 & 5.29626 & 3.84147 & 3.84147 \\
\hline
\end{tabular}

Table $3 b$

Seasonal cointegration test results

\begin{tabular}{llcc}
\hline Hypothesized no. of CE(s) & Eigenvalue & $\lambda$ max statistic & $\lambda$ max test at $5 \%$ \\
\hline None $^{\mathrm{a}}$ & 0.064087 & 13.71008 & 11.3 \\
At most $1^{\mathrm{a}}$ & 0.024934 & 5.22680 & 4.2 \\
\hline
\end{tabular}

${ }^{\mathrm{a}}$ The critical values are gathered from Darné [16].

to check it, we regress $\Delta Z_{t}$ on $Z_{t-1}$ and calculate the value of the usual $t$-statistics. The value of the periodogram-based test is -1.985 . The critical values are -3.43564 at the $5 \%$ level and -3.12867 at the $10 \%$ level. Therefore, we clearly fail to reject the null of no-cointegration. ${ }^{3}$

To sum up, even if the evidence for the conventional tests is mixed, the periodogram-based analysis suggests that the CPI and WPI indexes are indeed not cointegrated. There might be various reasons for the discrepancy of the test results. One possible reason for this is that the conventional tests require estimation of too many parameters to address the dynamics of the series with AR parameters. Moreover, addressing seasonality requires estimating additional parameters. However, the periodogram-based method is seasonally robust and requires no parameter estimation except for the variance (any consistent estimator of the variance can be used in the test statistics). These may account for the differences in the test results (see, Ref. [12] for details).

\subsection{Short-run analysis}

In order to assess any short-run relationship between the CPI and the WPI, the logarithmic first differences of each series were regressed on each other. If the logarithmic first difference of the WPI is regressed on the logarithmic first difference of the CPI, the estimated coefficient of the logarithmic first difference of the CPI is 0.8818 with a $t$-statistics of 20.46 . This suggests that indeed there is a short-run relationship between these two indexes. However, we reject that this relationship is one-to-one. That is, we reject the null hypothesis that the coefficient of the logarithmic first difference of the CPI is one.

\footnotetext{
${ }^{3}$ One may look at Berument et al. [18] for the critical values.
} 


\section{Discussion and conclusion}

The evidence presented here suggests that the Engle and Granger [6] and the Johansen [7] conventional cointegration tests give mixed results. However, the periodogram-based analysis clearly suggests that there is no long-run relationship between these indexes. Thus, we may claim that these series are not cointegrated. Having no long-run relationship is also parallel with the findings of Basu [2], Clark [3] and Kim [5]. While there is also a short-run relationship between these two indexes, this relationship is not one-to-one.

There is a big debate concerning the price level targeting versus inflation targeting. It is argued that a policy that targets the price level generates too much volatility in output and prices in the short run. The reason for this is that price level targeting requires that prices be returned to their previous level after every shock; however, in the long run, prices are fully predetermined. On the other hand, a policy that targets the inflation rate produces less volatility in the short run because it accommodates unanticipated shifts in prices, and requires only that the inflation rate be returned to its previous level. Therefore, prices are highly uncertain in the long run, resulting in a trade-off between price level targeting and inflation targeting (see, for example Ref. [19]). Not having a long-run relationship between the two price indexes means that the existence of price stability in one index does not guarantee price stability in the other index. Therefore, committing to price level targeting may not bring the benefit of price targeting for the whole society, including firms and consumers. However, the existence of a short-run relationship (WPI- and CPI-based inflations move together) brings the benefits of inflation targeting. Therefore, the policy choice should be inflation targeting not price level targeting for the Central Bank.

\section{References}

[1] K.M. Murphy, A. Shleifer, R.W. Vishny, Building blocks of market clearing business cycle models, NBER Macroecon. Annu. (1989) 247-286.

[2] S. Basu, Intermediate goods and business cycles: implications for productivity and welfare, Am. Econ. Rev. 85 (1995) 512-531.

[3] T.E. Clark, The response of prices at different stages of production to monetary policy shocks, The Rev. Econ. Stat. 81 (3) (1999) 420-433.

[4] K. Doroodian, R. Boyd, The linkage between oil price shocks and economic growth with inflation in the presence of technological advances: a CGE model, Energy Policy 31 (10) (2003) 989-1006.

[5] J. Kim, Short run real exchange rate dynamics: a SUR approach, Appl. Econ. Lett. 11 (2004) 909-913.

[6] R.F. Engle, C.W.J. Granger, Cointegration and error correction: representation, Estimation Test. Econ. 55 (1987) 251-276.

[7] S. Johansen, Statistical analysis of cointegration vectors, J. Econ. Dyn. Control 12 (1988) 231-254.

[8] A. Maravall, Unobserved components in econometric time series, in: M.H. Pesaran, M.R. Wickens (Eds.), Handbook of Applied Econometrics, vol. 1, Blackwell, Massachusetts, 1995, pp. 12-72.

[9] A. Hecq, Does seasonal adjustment induce common cycles?, Econ. Lett. 59 (1998) 289-297.

[10] G. Cubadda, Common cycles in seasonal non-stationary time series, J. Appl. Econ. 14 (1999) 273-291. 
[11] Y.-W. Cheung, F. Westermann, Sectoral trends and cycles in Germany, Empirical Econ. 28 (1) (2003) 141-156.

[12] Y. Akdi, Periodogram Analysis for Unit Roots, Ph.D. Dissertation, NCSU, USA, 1995.

[13] Y. Akdi, D.A. Dickey, Periodograms for unit root time series: distributions and tests, Commun. Stat. 27 (1) (1998) 69-87.

[14] J.D. Hamilton, Time Series Analysis, Princeton University Press, Princeton, NJ, 1994.

[15] P.H. Franses, B. Hobijn, Critical values for unit root tests in seasonal time series, J. Appl. Stat. 24 (1) (1997) 25-47.

[16] O. Darné, Seasonal cointegration for monthly data, Econ. Lett. 82 (2003) 349-356.

[17] S. Johansen, E. Schaumburg, Likelihood analysis of seasonal cointegration, J. Econ. 88 (1999) 301-339.

[18] H. Berument, Y. Akdi, C. Atakan, An empirical analysis of Istanbul stock exchange sub-indexes, Stud. Nonlinear Dyn. Econ. (2005) forthcoming.

[19] G. Srour, Price-Level versus Inflation Targeting in a Small Open Economy, Bank of Canada Working Paper 01-24, 2001. 